\title{
Freelance in Modern Russian Society: Job Search Through the Internet and by Means of the Internet
}

\author{
Anatoly Gretchenko ${ }^{1,2, *}$, and Alexander Gretchenko ${ }^{1}$ \\ ${ }^{1}$ Plekhanov Russian University of Economics, 117997 Moscow, Russia \\ ${ }^{2}$ Financial University under the Government of the Russian Federation, 125993 Moscow, Russia
}

\begin{abstract}
Freelancing is largely based on finding a job through the Internet and by means of the Internet, which allows you to open up new opportunities for the Russian economy and make structural changes to it. But the attitude of Russian society to the new form of employment is still poorly understood. At the moment in Russia, freelancing is at the stage of development and its further development depends on the attitude of the society towards this type of employment. Today, Russian society is undergoing especially important changes in connection with the pandemic, which turned out to be an unexpected test for every person, as well as for the whole society. The self-isolation regime has strongly affected the economic spheres of life, confronted companies with remote work, and people with an understanding of all the positive and negative aspects of working outside the office. The hypotheses put forward have been partially confirmed. In modern Russian society, the attitude towards the freelancers is rather neutral, but the share of positive assessments is also high. A small proportion of respondents expressed a negative attitude towards the freelancers, which indicates an overall good attitude towards freelancing. Therefore, the main goal of this article is to identify the attitude towards freelancing in modern Russian society.
\end{abstract}

\section{Introduction}

It is difficult for a modern person to imagine what will happen with him, his family, city and even the state in the nearest future. He often has no idea even about tomorrow. As a "defensive reaction" against rapid unprecedented transformations in the world, such a life strategy as flexibility is being developed. Willingness to change allows a person to focus primarily on short-term plans and on the nearest future.

This was especially evident during the Covid-19 pandemic, when many people were left out of work or unemployed indefinitely. The labor economy began to undergo great changes. There have been significant changes in the strategy of the Russian person.

\footnotetext{
*Corresponding author: gai51@list.ru
} 
Freedom is implied by a life strategy with a focus on the nearest future. In such a case, dependence on constant office work and the boss does not give the flexibility discussed earlier. First of all, a person cannot manage his own time if he has a clearly established work schedule. This already speaks of lack of the freedom. Therefore, for a modern person, freelancing is becoming an increasingly relevant solution to this problem.

Freelancing is largely based on finding a job over the Internet and by means of the Internet. The largest platform where the performers and the employers meet is FL.ru. There are also many others, whose audiences may not overlap or partially overlap. However, it should be noted that since the beginning of the self-isolation regime in Moscow and other regions of the country (March 2020), the number of searches for "FL.ru" began to sharply increase. In March 2020, this number was 22,816, and in June 2020, it equaled to 67,432, which is 3 times more. In the same period last year, the number of requests was only 15,576. Anyway, the number of requests related to the work of a freelancer has also increased $[1,2]$. This can open up new opportunities for the economy and bring structural changes to it. But the attitude of Russian society to the new form of employment is still poorly understood. Therefore, the main goal of research in this direction is to identify the attitude towards freelancing in modern Russian society.

The authors of the article put forward the following hypotheses:

- most (over 50\%) of the population are not aware of freelancing as a type of employment;

- modern Russian society expresses positive assessments of freelancing;

- residents of large cities are more positive towards freelancing than people from small towns and villages;

- older people (60 years and over) are more negative in relation to freelancing than young people (18-35 years old).

"Freelance" is still a partly slang expression and has not yet entered the scientific literature in full. Much more often you can see such concepts as "free employment", "remote work", "self-employment" and others. So, some Russian scientists, for example, D.O. Strebkov and A.V. Shevchuk distinguish three theses that fully reflect the concept of "freelance". The first thesis: "Freelance is a form of self-employment." In this thesis, there is a similarity with entrepreneurial activity, since in these cases the self-employed people have an unstable income and are completely dependent on the success of their activities in a certain period of time. And the most important element is that all work is carried out individually, without the involvement of other employees or organizations [3].

The second thesis: "Freelancer is an independent worker." The main feature of freelancing is independence. Moreover, it manifests itself in everything: independence from the workplace, from the location (country, city), from the boss, from the work schedule, etc. A freelancer, as a rule, works with several clients at once, which also manifests his independence in choosing the clients. This differentiates the freelancers from the selfemployed people. This is due to the fact that often self-employed workers have been cooperating with one or two organizations for a long time, which takes control over them, both financially and organizationally. Then a self-employed person can "turn" into an employee of the company, but be without an official employment, and remain "on a contract", which is beneficial to the employer, since part of the taxes can be avoided [4].

"A freelancer is a highly qualified professional." This is the third term put forward by the authors [5-6]. But it should also be noted that over time, such areas of activity that do not require higher education, but are based on talent and experience, have become related to freelancing. These can be the photographers, copywriters, beauty professionals and others [7].

It should be noted that in foreign countries of America and Europe, freelancing is much more developed than in Russia, due to the fact that its foundations are only being formed in 
the Russian economy. This stage in other foreign countries has been completed 15-20 years earlier [8-13].

Free-lance.ru is the first Russian-language freelance exchange, launched on May 14, 2005. Now this date has become the official Freelance Day in the Russian Federation. The Russian community has been formed, which, as noted by the domestic researchers, has grown into an independent trade union $[14,15,16]$.

Today, Russian society is undergoing especially important changes in connection with the pandemic, which turned out to be an unexpected test for every person, as well as for the whole society. The self-isolation regime has strongly affected the economic spheres of life, confronted companies with remote work, and people with an understanding of all the positive and negative aspects of working outside the office. This stage can become a turning point in the attitude of people towards non-standard types of employment and an impetus to the accelerated development of freelancing in Russia. But this is possible only with a positive assessment of this type of the employment by the society $[17,18,19]$.

\section{Materials and methods of sociological research of freelancing}

A survey on attitudes towards freelancing has been conducted by the authors of the article in the period from 2018 to 2020. During the onset of a pandemic coronavirus infection recognized by the World Health Organization and associated with its spread in some countries, the first survey among Russian citizens was conducted on February 24, 2020. At this time, the self-isolation regime has not yet been introduced in the regions of Russia, so it is worth paying attention to the survey conducted on April 30, 2020. This survey is aimed at studying the attitude of the population towards the remote work, which is faced by part of the country's population. Thus, the attitude towards the remote work can reveal the attitude towards freelancing, since these forms of employment have similar features [19, 20, 21].

Using the method of telephone interviews, which involved 1600 respondents from various socio-demographic groups. For this sample, the maximum error size with a $95 \%$ probability does not exceed $2.5 \%$.

It should be noted that a large number of factors can influence the attitude of people towards freelancing. These include: gender, age, educational level, type of locality, awareness of non-standard work activities and the desire to become a freelancer. The data necessary for the analysis were presented in the database, and the respondents were asked about their attitude towards freelancers in general. This allowed us to analyze the general mood of the population regarding freelancing, determine correlations and analyze contingency tables using the Chi-square test.

The second database made it possible to analyze the level of digital competencies. This also affects the attitude towards freelancing, since it is impossible without the use of the Internet, digital platforms, specialized programs, etc. This database contains the most relevant information that allows you to identify the attitude towards remote work, which is the "ancestor" of freelancing. People who switched to remote work during the period of self-isolation were able to give a new assessment of the attitude towards this type of employment since they were directly able to at least partially experience the positive and negative aspects of working remotely.

As noted in the introduction, the number of freelance queries has been on the rise since March 2020. This means that interest in freelancing is also growing, but it still cannot be said that the positive attitude in society towards this relatively new phenomenon is also growing.

The analysis was carried out using the IBM SPSS Statistic program. 


\section{Result and discussion on the attitude of the country's population to freelancing}

To determine the attitude of the country's population to freelancing, first of all, it is necessary to understand the awareness of citizens about this type of work. When asked "Have you ever heard the word" freelancer before? " 65.2\% of respondents answered "I find it difficult to answer / don't know". This indicates a low level of public awareness.

The results of calculating the Chi-square test showed a close relationship between the type of settlement in which the respondent lives and his awareness. Pearson's Chi-square value was 180.307 at 6 degrees of freedom, and the asymptotic significance was 0.000 . In the countryside, only $9 \%$ were able to give any definition of a freelancer, while in cities with more than a million people, 51.9\% coped with the task (Fig. 1).

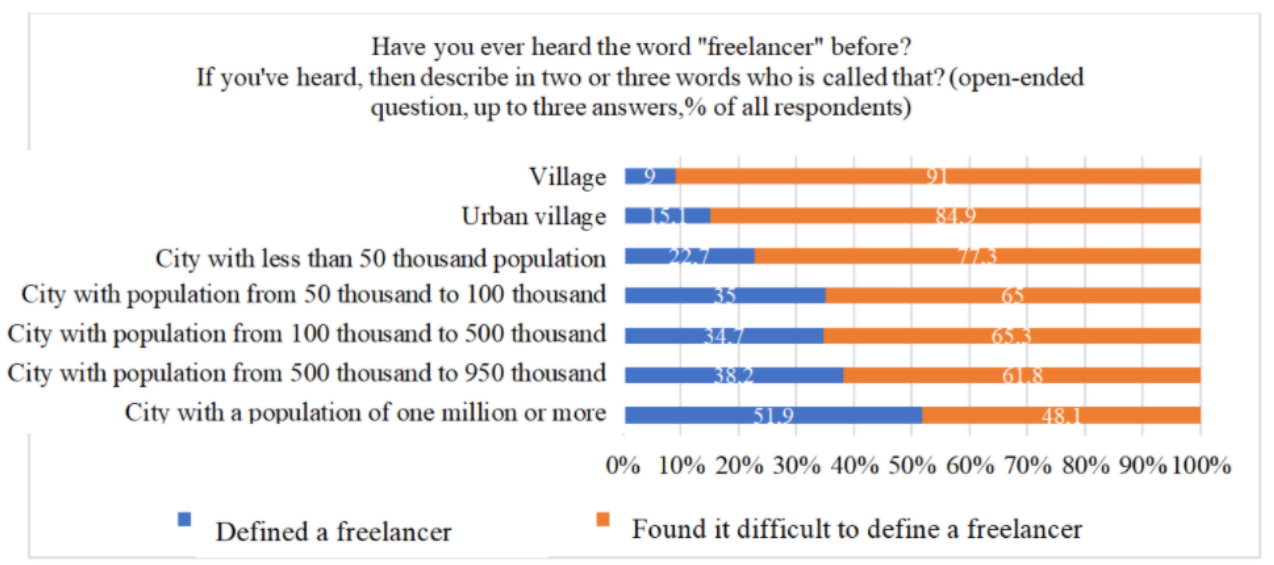

Fig. 1. Have you ever heard the word "freelancer" before? If you've heard, then describe in two or three words who is called in that way?

In order for all respondents to equally understand freelancing, they were given a definition of freelancing as a group of persons related to the employees.

The question was also asked "How do you generally feel about the freelancers?" The results are shown in Figure 2. The results of the survey indicate that a half of the respondents (49\%) are indifferent to the freelancers, $41 \%$ gave positive ratings. Only $7 \%$ expressed negative attitude towards the freelancers. The same part of people who remained indifferent probably did not face this type of employment or do not have negative experiences associated with freelancing. Therefore, it can be argued that the general population will not experience negative emotions in relation to freelancing. This makes it possible to develop this direction. 
How do you feel about freelancers in general? (closed-ended question, one answer, $\%$ of all respondents)

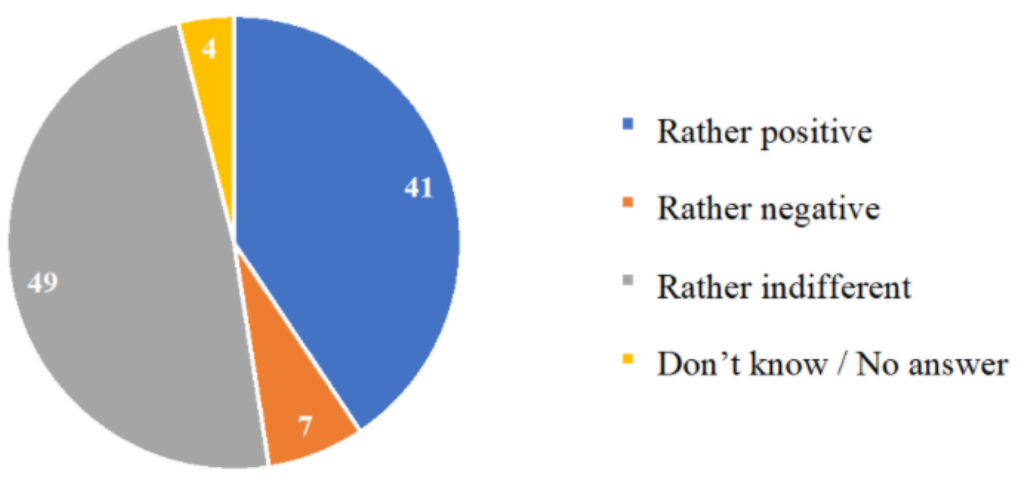

Fig. 2. "How do you generally feel about the freelancers?"

Next, let's look how an attitude towards the freelancers depend on different demographic characteristics of the respondents. Age has a big influence on attitudes towards the freelancers. Chi-square test showed a significant relationship thereof. The criterion value is 80.999 at 12 degrees of freedom, and the asymptotic significance tends to zero.

Figure 3 shows that with age, negative assessments become much more (18-24 years old - 1\%; 60 and older - 12\%). It is also interesting to note that people aged 25-34 express significantly more indifference towards freelancers than positive attitude. And the respondents aged 35-44 are the only group where the number of positive assessments exceeded indifference.

How do you feel about freelancers in general? (closed-ended question, one answer, $\%$ of all respondents)

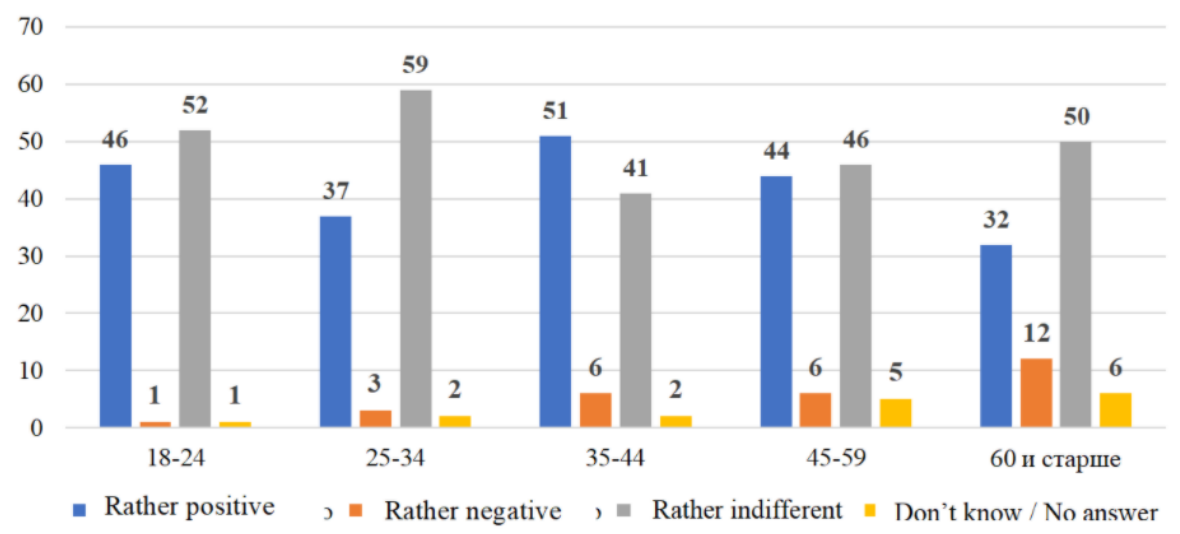

Fig. 3. "How do you generally feel about the freelancers?"

Relationship between attitudes towards freelancers and educational attainment was weak. The value of Cramer's V criterion is equal to 0.106 , and the significance tends to zero. Thus, education is not a significant factor in determining a person's attitude towards the freelancers.

Since awareness differs in different types of the localities, the attitude towards freelancing is different. Chi-square test showed a significant relationship between the attitudes towards the freelancers and the type of settlement of residence. The Chi-square 
test is 46.646 at 18 degrees of freedom, and the asymptotic significance is 0.000 , which allows an alternative hypothesis to be accepted.

In rural areas and small towns, there is a high proportion of negative assessments, as well as difficulties in answering (Figure 4). Every tenth person in a village or urban-type settlement has a negative attitude towards freelancing. People from million cities show a positive attitude $(46.9 \%)$ more often than people from smaller cities, as well as a neutral attitude (46.9\%). The ratings spread depending on the place of residence are rather ambiguous and requires more detailed study.

How do you feel about freelancers in general? (closed-ended question, one answer, $\%$ of all respondents)

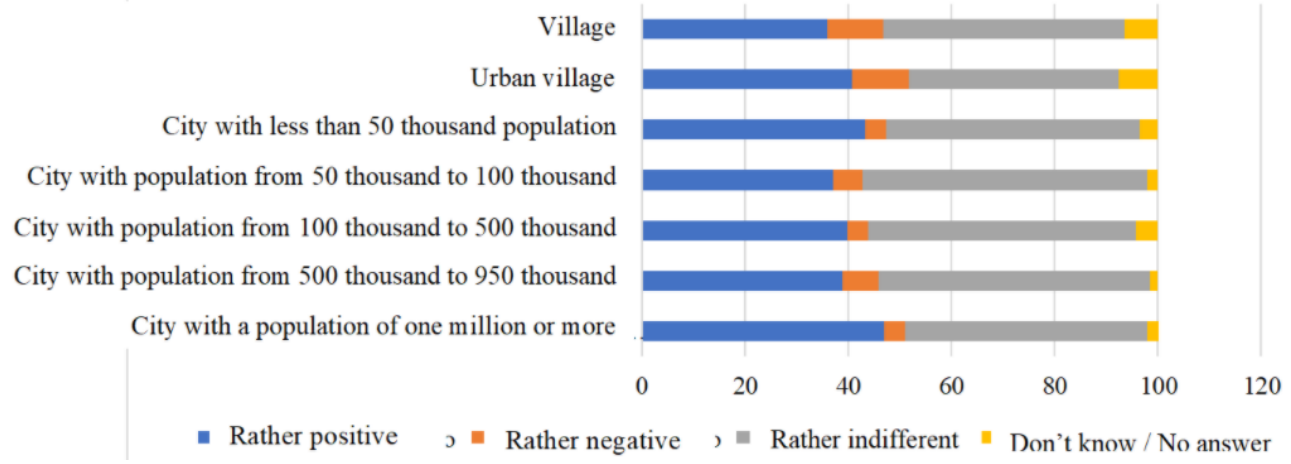

Fig. 4. "How do you generally feel about the freelancers?"

The most positive ratings are expressed by people who themselves would like to become the freelancers. The share of such respondents is $22.9 \%$ (Figure 5). Almost $70 \%$ would rather not want to become the freelancers. But there some professions that cannot be realized via the freelance, as well as other reasons that influence the desire to become a freelancer. However, despite all the reasons, almost a quarter of the Russians surveyed are ready to imagine themselves as the freelancers and are even going to implement this in the nearest future. According to the survey, $10.5 \%$ of the respondents identify themselves as self-employed or the freelancers. In the nearest future, growth is possible by $20.5 \%$. It is likely that those who, at the time of the survey, thought about freelancing only in the long term, could change their plans under the influence of self-isolation and the spread of remote work during this period.

Would you like or would not like to become self-employed or freelancer? (closed-ended question, one answer, $\%$ of all respondents)

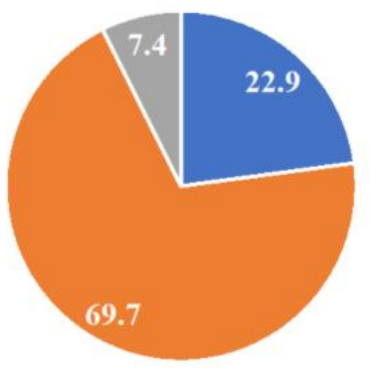

- Rather would like

- Rather would not like

" Don't know / No answer

Fig. 5. Would you like or would not like to become self-employed or freelancer?

During the period of self-isolation, some people, especially in large cities, were able to work remotely. This became an opportunity to partially experience the positive and negative sides of freelancing. Therefore, those people who would like to become self- 
employed and freelancers could radically change their intentions. According to a survey conducted on April 30, 2020, 295 people who were transferred to remote work assessed it rather negatively (Figure 6). 36.2\% of the respondents felt themselves positively.

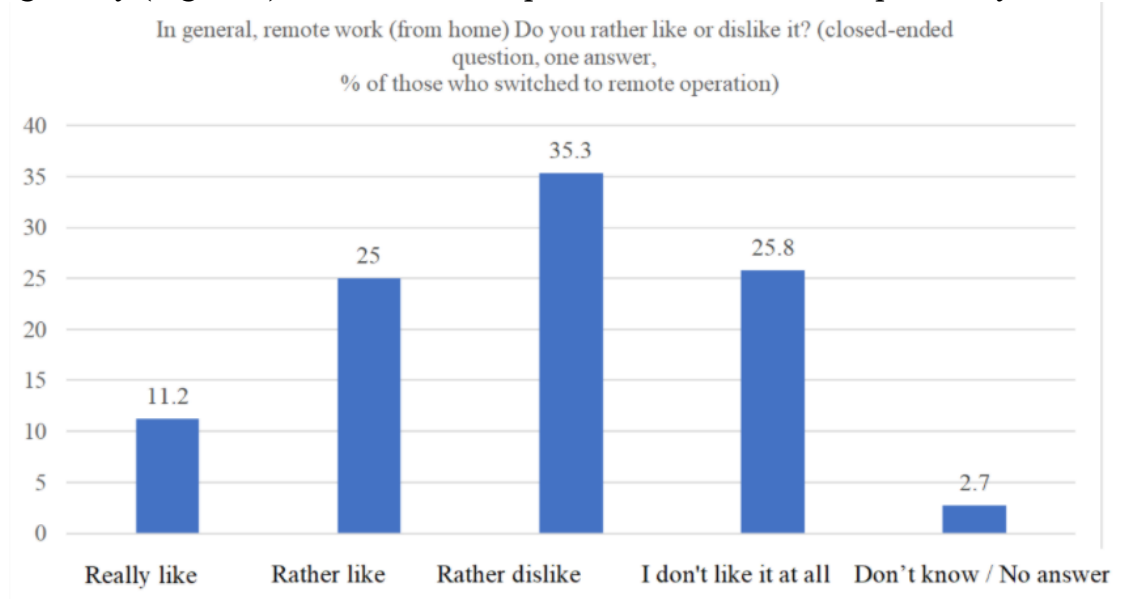

Fig. 6. Do you rather like or dislike it a remote work (from home) in general?

Thus, more than a third of the population rather liked working remotely, which is not much lower than the number of people who spoke positively about the freelancers in the previous survey (41\%). We can assume an accelerated growth of self-employed and freelancers in the coming years, since the population expresses a positive attitude and readiness to accept new types of employment.

\section{Conclusion}

The hypotheses put forward have been partially confirmed. In modern Russian society, the attitude towards the freelancers is rather neutral, but the share of positive assessments is also high. A small proportion of respondents expressed a negative attitude towards the freelancers, which indicates an overall good attitude towards freelancing.

At the same time, the hypothesis was confirmed: a significant part of Russian society is not aware of the type of work activity as freelancing. This can become a problem in the development of freelancing, since the understanding of the term by the majority of society is a reference point for the further functioning of this phenomenon. The concept of freelancing should become accessible to everyone, then a large proportion of citizens will be able to consider this type of activity for themselves as potentially possible. By doing so, freelancing can help reduce unemployment and open up new business and economic opportunities.

The hypothesis that people from large cities express a more positive attitude towards freelancing than people from small towns and villages has been partially confirmed. Although the Chi-square test showed a significant relationship, the structure of the distribution of the responses is rather complex and requires additional consideration.

The older people are, the more often they express a negative attitude towards freelancing. Thus, the last hypothesis has been confirmed. Older people are less involved in digitalization, they are less mobile and receptive to innovations, therefore, a new type of work activity, like anything new, more often causes them negative emotions.

It was also revealed that almost a quarter of the respondents would like to become the freelancers in the future. Freelance has great opportunities for development in Russia, and the number of freelancers will grow in the near future. 


\section{Acknowledgements}

This article was prepared as part of the government contract as requested by the Ministry of Science and Higher Education of the Russian Federation on the subject formulated as «Structural changes in economy and society as a result of achieving the target indicators of National projects, which provide opportunities to organize new areas of social and economic activity, including commercial, both in Russia and abroad» (project No. FSSW-2020-0010).

\section{References}

1. A.I. Gretchenko, A.A. Gretchenko. II International Scientific Conference GCPMED 2019 "Global Challenges and Prospects of the Modern Economic Development". European Proceedings of Social and Behavioural Sciences, 79, 430 (2019)

2. A.I. Gretchenko, A.A. Gretchenko, Digital economy and the new labor market: jobs, competencies and innovative HR technologies. IPM 2020. Lecture Notes on Networks and Systems, 161, 283 (2020)

3. D.O. Strebkov, A. V. Shevchuk, World of Russia, 1(24), 72 (2015)

4. D.O. Strebkov, A. V. Shevchuk, M.O. Spirina, Development of the Russian-speaking market for remote work, 2009-2014, 16 (2015)

5. D.O. Strebkov, A. V. Shevchuk, Sociological research, 1, 81 (2017)

6. V. S. Kharchenko, Sociological research, 4, 54 (2014)

7. E.V. Kozhevnikova, V.S. Kharchenko, Proceedings of the IX International scientific and practical conference of young scientists: Youth in a changing world: challenges of our time, 2, 79 (2018)

8. M.B. Arthur, D.M. Rousseau (eds). The boundaryless career: a new employment principle for a new organizational era (1996)

9. D. Osnowitz, Freelancing Expertise: Contract Professionals in the New Economy (2010)

10. Tourangeau R., Edwards B., Johnson T.P., Bates N., Wolter K.M. (eds). Hard-toSurvey Populations (2014)

11. M.I. Nadiri, B. Nandi, K.K. Akoz, Telecommunications Policy, 42(6), 433 (2018)

12. G.S. Banu, Proceedings of the 11 th International Conference on Interdisciplinarity in Engineering (INTER-ENG), Procedia Manufacturing, 22, 906 (2018)

13. E. Domínguez, B. Pére, Á.LRubio, M.A.Zapata, Computer Standards \& Interfaces, 64, 24 (2019)

14. B. Akhmadeev, S. Manakhov, Journal of Security and Sustainability, 5(2), 269 (2015)

15. Akhmadeev, S.V. Manakhov, Espacios, 39(18), 31 (2018)

16. N. Moiseev, B.A. Akhmadeev, Journal of Interdisciplinary Economics, 29(2), 176 (2017)

17. A.I. Gretchenko, E.E. Nikitskaya, A.A. Gretchenko, O.G. Demenko, Journal of Advanced Research in Law and Economics, 9, 3(33), 481 (2018)

18. A.I. Gretchenko, E.E. Nikitskaya, M.A. Valishvili, Gretchenko, A.A., Revista Espacios, 39(21), 13 (2018)

19. Gretchenko, I.V. Gorokhova, O.G. Demenko, A.A. Gretchenko, Journal of Advanced Research in Law and Economics. Quarterly, 9(4),1243 (2018) 
20. A.I. Gretchenko, O.G. Demenko, A.A.Gretchenko, Journal of Advanced Research in Law and Performance Indicators Management. Computer Standards \& Interfaces, 64, 1249 (2018)

21. G. Beliakov, A. Gretchenko, A. Ryzhaya, A. Shpak, S. Belyakov, International Journal of Supply Chain Management, 8(6), 1035 (2019) 